\title{
Analysis on Concrete Practice of Garden and Horticulture in Agriculture Development
}

\author{
Xin Liu \\ Kunming University, Kunming, 650214, China
}

Keywords: Gardens and horticulture, Concrete practice, Agriculture development.

\begin{abstract}
With the continuous development of economy and the gradually improved living standard, people pay more attention to the environmental quality of cities, so garden and horticulture have been the concern of the citizens. Garden and horticulture are different but closely related in concept. Garden and horticulture can beautify agricultural scenery, inherit agricultural culture and innovate agricultural economy. This paper analyzes the important functions of garden and horticulture in agriculture development to provide some references for the relevant researchers.
\end{abstract}

\section{Introduction}

Garden city has a prominent feature of the city whose suburbs have towns, towns have forests, , and realize the coordinated development of man and nature. Planting three-dimensional planting leisure agricultural park is to make full use of space, time and other aspects of the cultivation conditions to achieve agricultural planting mode of high quality and high efficiency, energy saving and environmental protection, is to discard the traditional agricultural farming single plane. The stereoscopic planting adopts the technique of garden art design, which makes the monotonous crops in people's eyes become real and touching gardening works, and makes people feel the high-quality leisure agriculture. The stereoscopic planting of garden art includes three aspects: space, color and shape. In space, mainly refers to the different types of crops, different growth characteristics, rational use and deployment in time and space. For tall crops, dwarf crops can be planted, and sunny crops can be planted on the sunny side, while shade crops can be planted on the back. Grasp the difference of crop characteristics, improve the land utilization rate of leisure agriculture, and form a multi-level planting structure. The stereoscopic color is mainly represented by the harmony and contrast between the cool colors and the warm colors. Most of the modern landscape plants use their own color, a large number of warm and cold, color contrast, a short period of time to highlight the ornamental effect, and left a deep impression. Applying this method to leisure agriculture, the best flowering period of crops can be used to achieve the color of garden art. For example, seeds of rape are sown under peach trees. Because of their similar flowering period, pink and white peach and lemon yellow and green bottom embellishment, make the color fuller rich layering. The shape of the three-dimensional landscape in the art of the main application of different forms to show the theme. It can also be used for shaping and pruning crops in recreational agriculture without affecting production.

\section{Concepts and Relationship of Garden and Horticulture}

Concept of Garden. The use of engineering technology and art in a certain area, through the transformation of the terrain, planting trees and flowers, construction and layout of Park Road to create such a beautiful natural environment and recreation is called garden. Among the Chinese traditional architecture, classical architecture is one of the most important achievements. An art form in traditional Chinese culture, which is deeply influenced by traditional ritual culture. Through the topography, mountains and rivers, buildings, flowers and trees as a carrier, showing the spiritual culture of the human subject. Gardens have many extension concepts: Garden community, Garden 
street, garden city, national garden, county town and so on. Modern lifestyle and living environment have urgent functional and artistic requirements for gardens. It is playing an increasingly important role in our modern life and for the future development of the people. Chinese garden has a long history, is the ancient China architectural art treasures, landscape art is a long history, the art forms are mainly influenced by the ideology of the ruling class and the Buddhist, painting, poetry, fierce competition for the ruling class that country was divided, and the influence of Taoism and Buddhism flourished, the metaphysics, then the literati, or for pleasure, or abstinence, or travel landscape, resulting in the formation of natural aesthetic view, also for the treatment of garden features natural taste of rural landscape. People have come to realize the transformation of the natural environment of the landscape art, and gradually strengthen the use of gardening, the landscape plan, for the transformation of their living environment, and constantly improve their own quality of life.

Concept of Horticulture. Horticulture is the cultivation, breeding, production and management methods of fruit trees, vegetables and ornamental plants. It can be divided into fruit trees, gardening, vegetables, gardening and ornamental gardening. The term refers to the original horticulture, plant cultivation in the garden of the protection fence. Modern gardening has long broken this limitation, but it is still more intensive than other crops. Horticulture is an integral part of farming in agriculture. Horticultural production is of great significance for enriching human nutrition and beautifying and reforming human living environment. Whether it is in the courtyard, gardens, roof, balcony or indoor space, surrounding and other related facilities are to artificially create beautiful living environment clean and elegant and comfortable working conditions. It plays an important role in cultivating good morals and social customs and developing modern socialist material civilization and spirit. The purpose of specialized horticulture is to produce high-quality crops in order to achieve maximum economic benefits. The cultivation of general horticulture is mainly ornamental, supplemented by production. Therefore, the main emphasis on scientific management, which in addition to scientific requirements management, but also pay attention to the art of the application of general requirements, science and art combine together, which showed double ornamental and practical value. In recent years, with the constant enhancement of people's environmental awareness, in addition to landscaping, landscaping to every corner of the living environment in the fashion is gradually formed, so gardening content with the trend has been limited to refer to the use of ornamental plant cultivation related technology, began to pay attention to art, make to the development of ornamental art the direction of. Gardening is a basic form to meet the needs of gardens, and it can effectively solve the problems of garden plants.

Relationship of Garden and Horticulture. In the process of landscape gardening development, its concept is gradually differentiated from modern times. With the continuous development of society, the two have been divided into two separate disciplines. The garden, which is mainly from the global landscape of planning and design of landscape, according to people's aesthetic appreciation, different material related to the reasonable collocation, thus constitute a whole garden. In the actual design process, not only will strengthen the utilization of natural resources, but also strengthen the use of cultural elements. Generally speaking, landscape architecture pays more attention to aesthetics and cultural connotations. Gardening pays more attention to the cultivation and maintenance of plants. It has a strong scientific nature and is not required for the overall situation. It belongs to the garden. Generally speaking, gardening is the foundation of garden, and gardening is the internal motive force of horticulture development. Therefore, in the garden design and construction, plants occupy an important position. At this point, the importance of gardening is very important. If there is no gardening, the garden will lose its connotation and cannot meet the needs of the modern people. In the process of landscape design, not all plants can be applied in the landscape, and the staff can choose the proper local plants according to the actual situation of the city garden to ensure good results. For example: in the selection of seedlings, should be timely in accordance with local climate conditions, geological characteristics of choice. In general, poplar, elm, willow and various evergreen trees are preferred. The flowers in the selection process, should the growth cycle of flowers be considered free, usually choose the longer growth period and long frost-free flowers. Grass should select some 
trampling resistant and tough species in the selection process, which shows the importance of horticulture and enhances the connotation of gardening.

\section{Applications of Garden and Horticulture in Agriculture Development}

Beautify Agricultural Scenery. Some landscape architects use the elements of agriculture in the design of urban landscape, and add the elements of landscape to urban park design. Some designers pay attention to the use of local agricultural landscape features, such as the terrace as an important form of landscape performance, applied to the landscape layout. Some designers in order to highlight the landscape to the people in the feeling of real life, the laws of nature and development of the agricultural landscape represented by a clever capture, the landscape design for the atmosphere will be a continuous cycle of change, landscape system changes with the change of the system of nature. More for other designers to create a strong sense of place and identity, in landscape design, the extraction and processing of, to the geographical and cultural characteristics of the elements into, and preserved under the symbol culture and distinctive regional features of the part. People in accordance with the aesthetic needs of their own, or to artificial modification of natural water bodies, or direct construction of artificial water, to beautify the human living environment, every kind of water works, water from the material function gradually become both the function of art features, from and become a part of the landscape art, is unique taste. The development of facility agriculture in our country needs a certain process, and it is still in the initial stage. The government has introduced a series of preferential policies, but its service system and sales channels cannot provide basic guarantee for farmers. The agricultural technical service system of our country is not perfect, and the production, processing and sale are disjointed, and cannot be organically combined. The management system and mechanism cannot adapt to the development of the market economy. Whether the government under the science and technology popularization system, or area farmers group's technology service organization network is not perfect. In addition, the scientific and technological quality of the producers is low, thus increasing the risk of the production of Facilities Horticulture, improving the level of farmers' science and technology, strengthening the construction of technical service system, and improving the guarantee system of facilities agriculture. This is the basis for the development of gardening and gardening, and also the guarantee to improve the income of farmers. In the Chinese agricultural society in the long term, Chinese long agricultural civilization, created the ancestors of the heaven to eat seasonal consciousness, and seasonal agricultural production is also popular with consciousness. These general holds the masses at the age of ideas, seasonal consciousness, rise and into the realm of aesthetics, on the performance of the spring and summer, autumn and winter four when the particulars of the world of aesthetic generalization.

Inherit Agricultural Culture. The agricultural landscape is the upgrading of the taste and quality of landscape architecture, as well as the inheritance and continuation of the historical context. Agricultural landscape is the materialized carrier of regional development process and regional culture. Because the agricultural landscape contains folk customs, historical culture, economic and social, and people's life, production and other factors. Experience in the city people to reflect the agricultural growth, especially in agriculture almost absolutely ignorant of city children, planted by city park in the green design at the beginning of the reserved land on various crops for a preliminary understanding of agricultural production. The designer combines the modern landscape and the agricultural experience skillfully, and the design technique is natural and tactful. Through the experience of agriculture, people have some experience in shaping the regional history of agricultural landscapes. Whether it is China traditional garden royal gardens or private houses, the pursuit of appreciation of nature and the creation of the various types of scenery are organized and arranged according to the laws of nature, not only with water, rocks, trees and flowers to reproduce the natural amorous feelings, make people in the garden will be able to enjoy the rich and colorful natural beauty, and also with the weather, the sky clouds and other natural phenomena to create the ethereal and angry, can make the landscape and nature of the integration of the myriads of changes appreciate the natural beauty, rich and colorful. A beautiful ecological environment China landscape creation, 
embodies the highest agricultural nation in the most elegant living wisdom, strengthen the pursuit of natural environment and shelter dependent mentality, promote the ecological environment consciousness of people early, this strong environmental awareness, for thousands of years, have been clamoring to sprout generations of Chinese my heart is active in all aspects of traditional agricultural culture. Gardening and gardening become the spiritual resources for sustainable development of human being.

Innovate Agricultural Economy. Facility horticulture is one of the most profitable industries in agriculture. It has enriched the urban and rural food basket and helped to solve the problem of vegetable supply during the winter and off-season in northern China, which has greatly increased the income of farmers. Facilities Horticulture provides an important way to adjust the agricultural industrial structure and make full use of light energy, thus saving a great deal of energy. It avoids the environmental pollution caused by greenhouse heating, promote agricultural production industry structure adjustment, promote the development of industry, made a historic contribution for the great living standards of urban and rural residents in the improvement of social stability. Protected horticulture is a systematic project, involving many technical fields. It must be studied and solved in a planned and step-by-step way, and gradually improved so that it cannot achieve the overall goal in just a few years. Compared with the developed countries of the modern agriculture, there is still a considerable distance, especially the production of greenhouse environment automatic control system, the tolerance to low temperature and weak light greenhouse varieties, long season cultivation and breeding technology and standardized factory standards, technical specifications and standards of greenhouse production, greenhouse production expert system, greenhouse production of small machinery and the covering material is a big difference distance etc.. So far, our facility horticulture is still a long way from the controllable environment, so it is a long-term task to strengthen the technical innovation and research in this area. For agricultural landscaping, construction and maintenance work are indispensable, both of which are interrelated and complementary. Construction is the most basic work of landscaping work, the quality of the construction will directly affect the future growth of trees and become useful, and the construction of the late maintenance management is also very important. Only when we do a good job in planting trees, that is, construction work, and do a good job in conservation work, can we better prevent natural disasters, and this is also more conducive to better economic results.

\section{Conclusion}

Garden and horticulture play a very important role in the development of society, especially in agriculture. Landscape gardening in our country needs to take economic benefits as the center and adjust measures to local conditions to realize diversification and specialization. We should take sustainable development as our goal and realize the industrialization and modernization of garden and horticulture.

\section{References}

[1] Yanping Li, Yiyong Zhang, Haicheng Yu. Gardening and Agricultural Application in Chengde Summer Mountain Resort [J]. Asian Agricultural Research, 2013, 5( 5) : 98-99+104.

[2] Mo Hongwei, Li Biao. Analysis of Landscape Gardening in Concrete Practice of Agriculture Development [J]. Times Agricultural Machinery, 2016, 43(10): 97-99.

[3] Zhou Ying, Nihamaitie. Hojar. Analysis of the “Trinity” Ecological Agriculture Sightseeing Garden Planning [J]. Times Agricultural Machinery, 2016, 43(3): 161-163.

[4] Xu Yong. Optoelectronic agriculture and its application in facility horticulture [J]. Journal of Shanxi Agricultural University (Natural Science Edition), 2016, 36(2): 77-84. 